\title{
Rádio Cognitivo como um Meio de Aumentar a Capacidade de Redes em Malha sem Fio
}

\author{
Ricardo Carvalho Pereira, Richard Demo Souza e Marcelo Eduardo Pellenz
}

\begin{abstract}
Resumo-A aplicação do modelo rádio cognitivo designado overlay é proposta para os enlaces de comunicação entre os nós de redes em malha sem fio. De acordo com modelo proposto por Jovicic e Viswanath, é possível ter duas transmissões simultâneas numa determinada região de interferência mútua. Deste modo, ganhos consideráveis de capacidade da rede podem ser obtidos. Para o caso simples de uma rede com topologia em cadeia, o ganho é de $30 \%$.
\end{abstract}

Palavras-Chave-Rádio cognitivo, redes em malha sem fio, capacidade.

Abstract-We propose the application of the overlay cognitive radio model to the communication of links within a wireless mesh networks. Based on the communication paradigm proposed by Jovicic and Viswanath, it is possible to have two concurrent transmissions in a given interference region. As as result, considerable network capacity gains are achieved. For the simple case of a network with a chain topology, the gain is as high as $30 \%$.

Keywords - Cognitive radio, wireless mesh networks, capacity.

\section{INTRODUÇÃO}

As redes em malha sem fio (WMNs) são vistas como uma opção para a solução de algumas das limitações e para a melhora do desempenho de redes ad hoc, redes locais sem fio, redes locais pessoais sem fio e redes metropolitanas sem fio [1]. De acordo com sua arquitetura, WMNs podem ser classificadas entre uma rede bem estruturada e uma rede $a d$ hoc. De um lado, cada usuário acessa um gateway de modo a estabelecer uma comunicação com a rede. Por outro lado, cada nó ou usuário pode alcançar seu destino diretamente, desde que esteja dentro da sua área de transmissão, ou atingílo via saltos de transmissão através dos nós adjacentes. Nas WMNs, cada usuário ou nó pode operar tanto como um host ou como um roteador sem fio, transmitindo pacotes de outros nós de modo que estes pacotes possam alcançar um gateway que não tem o nó originador dentro da sua área de cobertura.

As WMNs apresentam um conjunto de facilidades que as tornam um modelo interessante para redes futuras. Algumas delas se referem aos investimentos reduzidos para implantar uma rede nova e fazê-la crescer, porque a rede pode ser instalada e incrementada aos poucos. Os gateways podem ser adicionados conforme a necessidade de tráfego demandada pelos usuários. A confiabilidade é melhorada também, uma vez que a estrutura em malha da rede possibilita múltiplos caminhos para cada nó. Outra característica interessante das

Ricardo Carvalho Pereira e Richard Demo Souza, CPGEI, UTFPR, Curitiba-PR, Brasil, e-mails: carvalho.pereira@pucpr.pr, richard@cpgei.cefetpr.br.

Marcelo Eduardo Pellenz, PPGIA, PUC-PR, Curitiba-PR, Brasil, e-mail: marcelo@ppgia.pucpr.br.

Este trabalho foi parcialmente financiado pelo CNPq (472977/2007-5).
WMNs é o fato que a cobertura da rede aumenta com o número de gateways e usuários [2]. Estas facilidades estão catalisando o desenvolvimento de redes celulares multi saltos com objetivo de melhorar a cobertura, taxa de dados, desempenho de qualidade de serviço em termos de probabilidade de bloqueio de chamada, taxa de erro de bit, e justiça de qualidade de serviço para os usuários [3].

Diferente das redes ad hoc, o padrão de tráfego do usuário em uma WMN é essencialmente entre o usuário e um gateway [2]. Mesmo assim, há algum tráfego relativo a sinalização entre usuários de modo a permitir as funções de roteamento, configuração e procedimentos de controle, uma vez que uma WMN é considerada uma rede que, dinamicamente, se forma, se reconfigura, e se organiza [1]. Usuários podem ser móveis ou estacionários. Usuários móveis são capazes de descobrir diferentes redes e se conectarem desde que se percebam dentro da área de cobertura da WMN.

Normalmente a capacidade das WMNs é obtida baseado nos estudos de capacidade de redes ad hoc [1], a qual é afetada por vários fatores como a arquitetura da rede, padrão de tráfego, densidade de nós, mobilidade dos nós, etc. Em [4] limites analíticos inferiores e superiores de capacidade são determinados para o caso estacionário. A capacidade de bits por segundo por nó reduz significativamente quando a densidade dos nós aumenta, de modo que a capacidade tende a zero com o crescimento do número de usuários. Para um cenário móvel, em [5] é mostrado que a capacidade em bits por segundo por nó pode ficar constante na rede. Em [2] é demonstrado que a existência de gateways nas WMNs introduz gargalos na rede. Devido à presença destes gargalos, diminui a capacidade disponível por nó.

Além disso, vale ressaltar que apesar de haver vários estudos relativos à capacidade de redes ad hoc, muitas questões ainda estão abertas quando consideradas as diferenças entre WMNs e redes ad hoc, tornando difícil que se possa adotar as mesmas soluções. Aspectos estes como: uma estratégia para decidir o local ótimo dos gateways; uma estratégia de seleção ótima de roteamento; e otimização cross-layer para aumentar a capacidade da rede [7]. Prasad [8], por exemplo, abre uma nova perspectiva para melhorar o desempenho de redes sem fio para serviços multimídia, caso o conceito de layerless communications fosse aplicado, baseado na ruptura do projeto da pilha por camadas para um projeto de coexistência de todas as camadas em um único plano com máxima interação. Mais recentemente, uma nova abordagem de capacidade de redes ad hoc empregando característica de rádio cognitivo baseda em transmissão cooperativa foi proposta por Vu [9], de maneira que, sob certas condições, a capacidade por nó pode atingir um valor assintoticamente constante mesmo com o crescimemto 
da rede.

Neste artigo, discutimos a aplicação de um novo paradigma de comunicação para WMNs, o modelo rádio cognitivo. No princípio, rádios cognitivos foram vistos como uma solução promissora para o problema da ocupação intensa do espectro [10]. A idéia básica deste esquema é explorar a característica de baixa utilização de bandas do espectro licenciado, para assim acomodar comunicações secundárias (não licenciadas) de dispositivos sem fio sem atrapalhar a comunicação dos usuários primários (licenciados) do espectro de frequências. $\mathrm{O}$ conceito de rádio cognitivo pode ser implementado de maneiras diferentes, conhecidas como interweave, underlay e overlay [11], [12], sendo que, em todas há a preocupação de o desempenho do usuário primário do espectro não ser afetado pelo usuário secundário.

O modo interweave foi originalmente proposto por Mitola em [10], onde os usuários secundários exploram a parte do espectro que está temporariamente desocupada pelos usuários primários. O modo underlay permite transmissões simultâneas do primário e do secundário, mas estabelece que a transmissão do secundário não deve causar nenhuma interferência acima do chão de ruído do receptor primário [11]. O modelo overlay também permite transmissões simultâneas do primário e do secundário [11]. A idéia básica deste esquema é que o usuário secundário pode usar parte de sua potência para sua própria comunicação e o restante da potência pode ser utilizado para auxiliar a transmissão do primário. O modelo overlay também pode ser visto como um método de transmissão cooperativa e é designado como comportamento cognitivo por Devroye [13].

Estamos particularmente interessados em explorar o modelo overlay por causa de suas características especiais de permitir transmissões simultâneas dentro de uma determinada região de interferência mútua. Neste artigo investigamos o efeito, em termos de capacidade da rede, de aplicar o modelo overlay de rádios cognitivos entre nós de uma WMN. Nossos resultados numéricos mostram que o esquema proposto pode trazer ganhos de capacidade consideráveis. Além disso, um dos principais desafios do modelo rádio cognitivo, que é o conhecimento não causal pelo transmissor secundário da mensagem que será enviada pelo transmissor primário, é superado pela natureza sequencial das transmissões em uma WMN.

O restante deste artigo é estruturado da seguinte maneira. Na Seção II, fazemos uma discussão breve da capacidade de uma WMN simples. Na seção III, revisamos alguns modelos de comunicação rádio cognitivo encontrados na literatura. $\mathrm{Na}$ Seção IV, discutimos a aplicação do modelo de comunicação overlay de rádios cognitivos em uma WMN. A seção V apresenta resultados numéricos que mostram o potencial de melhora na capacidade devido ao uso de comunicação cognitiva entre os nós de uma WMN. A seção VI conclui o artigo.

\section{CAPACIDADE DE UMA WMN SimpleS}

Considere o caso de uma WMN que consiste de uma cadeia de nós. É assumido que somente um nó em uma determinada região (região de interferência) transmite por vez (assumindo uma única frequência por canal e sem o uso de técnicas de múltiplo acesso por divisão de código). A região

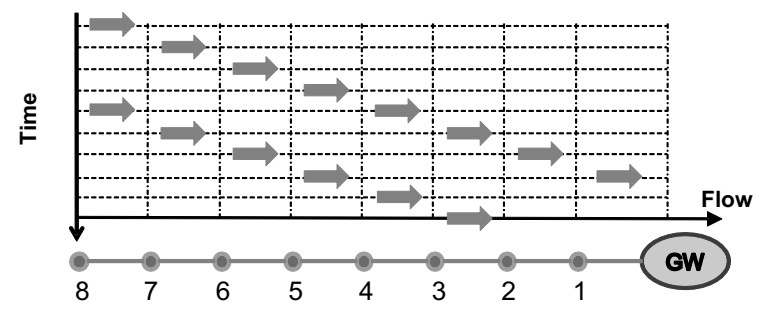

Fig. 1. Exemplo de uma WMN composta de uma cadeia de nós e um gateway. As setas representam os enlaces que estão transmitindo em um dado instante.

de interferência é definida pela distância de interferência que cada rádio pode provocar. Note que a definição de região de interferência é a mesma do que a definição de domínio de colisão em [2]. Além disso, é assumido que os nós não são capazes de transmitir e receber simultaneamente. Em outras palavras, os nós operam em modo half-duplex. O caso onde somente o nó mais distante em relação ao gateway transmite foi analisado em [6], enquanto que o caso em que todos os nós transmitem foi analisado em [2]. A análise feita nesta seção é baseada naquela apresentada em [6], uma vez que aqui será considerado que somente o nó mais externo da cadeia gera tráfego para o gateway. O caso do tráfego vir do gateway para o nó seria analisado da mesma maneira.

A capacidade da WMN considerada é uma função da extensão da interferência de um nó nos outros nós da cadeia. Por exemplo, suponha que o raio de transmissão seja a distância de uma unidade (salto) quando transmitindo com o nível máximo de potência, e que o raio de interferência seja o mesmo. Então, uma vez que os nós não transmitem e recebem ao mesmo tempo, em [6] é mostrado que a capacidade da rede é igual a $B / 3$, onde $B$ é a capacidade da comunicação ponto a ponto entre nós.

Se for considerado um cenário mais realista, onde o raio de interferência é maior que o raio de transmissão, então a capacidade da rede é menor. Suponha que o raio de interferência é duas vezes o raio de transmissão. Assim, se há uma transmissão entre dois nós, qualquer nó dentro do raio de interferência ditado por ambos o transmissor e o receptor não pode transmitir.

O motivo para incluir o raio de interferência do receptor é devido ao fato que este nó, ao receber uma transmissão, deve transmitir informações de retorno para o transmissor como procedimentos de contenção, reconhecimento, estado do canal, procedimentos de roteamento, entre outros. A Figura 1 mostra uma seqüência de transmissão ótima para esta rede, considerando o raio de interferência discutido acima. Na Figura, as setas representam os enlaces que estão transmitindo num determinado período e pode-se verificar que transmissões simultâneas ocorrem somente a cada quatro períodos de transmissão. Portanto, a capacidade da WMN na Figura 1, considerando que o raio de interferência é duas vezes o raio de transmissão, é igual à $B / 4$ [6].

Como enfatizado em [6], num cenário real usando rádios e protocolos reais, a capacidade seria ainda menor. Entretanto, como neste artigo é discutido um novo esquema teórico de 
transmissão para WMNs, o qual não é baseado em nenhum padrão de comunicação sem fio atual, consideraremos o caso simplificado de protocolos ideais.

\section{Modelos de RÁdio Cognitivo}

Rádios cognitivos são capazes de perceber o estado do canal sem fio, tomar decisões durante sua operação, e codificar dados usando uma variedade de esquemas de modo a explorar melhor as características do canal e mitigar a interferência [14]. Como já mencionado, o modelo rádio cognitivo pode ser classificado nos modos interweave, overlay e underlay [11], [12].

No modelo underlay, os usuários secundários protegem as comunicações dos usuários primários através da garantia de uma máscara espectral no sinal secundário, de maneira que a interferência gerada pelo dispositivo secundário esteja abaixo do chão de ruído ou de um limiar aceitável pelo usuário primário [11]. Neste modelo, assume-se que o dispositivo cognitivo tenha conhecimento da interferência gerada por seu transmissor nos receptores de todos os usuários primários. Devido a esta restrição imposta sobre os usuários secundários, este modelo é adequado para aplicações de curta distâncias [12]. Uma forma de empregar tal modelo é proposto por Taranto [15] através do uso de múltiplas antenas adaptativas a fim de atenuar o sinal do rádio cognitivo na direção do receptor do usuário primário.

O modelo interweave representa um sistema de comunicação sem fio inteligente que monitora periodicamente o espectro de rádio, detecta a ocupação nas diferentes partes do espectro e então, comunica-se de forma oportunista nas partes livres do espectro com mínima interferência para os usuários primários [12]. Este modelo requer que o transmissor secundário evite interferência para o usuário primário garantindo que suas transmissões ocorrerão somente em segmentos do espectro deixados livres pelo rádios primários. Em [16], os autores propõem o modelo interweave de duas chaves, no qual possibilita atividade do secundário somente se não houver atividade dos usuários primários dentro do raio de interferência de ambos transmissor e receptor sencundários.

A Figura 2 mostra o diagrama de blocos representativo do modelo de duas chaves como proposto em [16]. ST é o transmissor secundário e $S R$ é o receptor secundário, enquanto $P U$ é o usuário primário como visto pelo transmissor ou o receptor. $X_{S}$ é a mensagem que $S T$ quer enviar para $S R$. $S_{t}$ e $S_{r}$ são as chaves do transmissor e do receptor. $S_{t}\left(S_{r}\right)$ assume valor 1 quando não é percebida nenhuma atividade do usuário primário pelo transmissor (receptor). Se é percebida atividade do usuário primário, a chave assume valor $0 . Y_{S}$ é a mensagem recebida por $S R$, enquanto $Z_{S}$ é ruído aleatório. Neste modelo de rádio cognitivo, a capacidade do transmissor primário não é afetada pelo comportamento do transmissor secundário. Sejam $P_{S}$ a potência do transmissor secundário, e $\operatorname{Pr}(\theta)$ a probabilidade de um dado evento $\theta$. Baseado nessas definições, em [16] é fornecido um limite superior para a capacidade da comunicação do secundário com informações globais dos estados da chave, como reproduzido aqui:

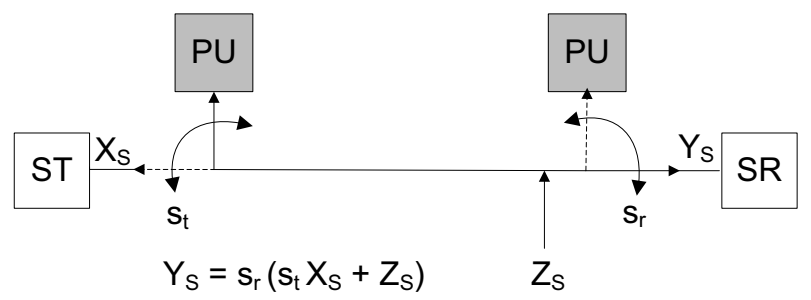

Fig. 2. Diagrama em blocos representando o modelo rádio cognitivo de duas chaves proposto em [16].

$$
C_{t s}\left(P_{S}\right)=\operatorname{Pr}\left(S_{t}=S_{r}=1\right) \log \left(1+\frac{P_{S}}{\operatorname{Pr}\left(S_{t}=S_{r}=1\right)}\right)
$$

Por sua vez, o modelo overlay é considerado como uma forma de transmissão cooperativa por Devroye et al [13], [17]. Os autores consideram o caso onde dois usuários cooperam assimetricamente para enviar duas mensagens independentes para dois receptores não cooperativos independentes, e o caso onde o transmissor secundário opera como um relay de modo a ajudar o transmissor primário. Em ambos os casos, o transmissor secundário deve ter a informação do estado dos canais e o conhecimento não causal da mensagem a ser transmitida pelo transmissor primário.

Jovicic and Viswanath [18] introduziram uma fórmula para a capacidade de ambos transmissores no modelo overlay de rádios cognitivos, muito similar ao encontrado em [13], [17], assumindo que não há modificação no processo de codificação e decodificação do usuário primário. Em outras palavras, o transmissor e o receptor primário não são avisados sobre a existência de transmissões de usuários secundários. A Figura 3 ilustra o modelo padrão normalizado considerado em [18]. $P T$ é o transmissor primário, $P R$ é o receptor primário, $X_{P}$ é a mensagem a ser transmitida pelo primário, $Y_{P}$ é a mensagem recebida pelo receptor primário, $Z_{P}$ é o ruído aleatório no receptor primário, a é o ganho do canal entre $S T$ e $P R$ (relativo ao ganho do canal entre $S T$ e $S R$, dado que a potência do ruído nos dois receptores sejam iguais) e $b$ é o ganho do canal entre $P T$ e $S R$ (também relativo ao ganho do canal entre $P T$ e $P R$ ). O modelo é todo normalizado em relação ao ganho do canal entre PT e PR (que é considerado o mesmo que entre ST e SR), e supõe potências de transmissão dadas por $(P p ; P s)$ e potências de ruído unitárias. O resto da notação segue as definições da Figura 2. $X_{P}$ e $X_{S}$ são ligados na Figura 3 para indicar que o transmissor secundário deve ter o conhecimento a priori da mensagem que será transmitida pelo primário. Em [18] é mostrado que, enquanto o transmissor primário não é afetado, o transmissor secundário pode atingir uma taxa tão alta quanto:

$$
C_{\text {over }}=\frac{1}{2} \log \left(1+\left(1-\alpha^{*}\right) P_{S}\right)
$$

onde

$$
\alpha^{*}=\left(\frac{\sqrt{P_{P}}\left(\sqrt{1+a^{2} P_{S}\left(1+P_{P}\right)}-1\right)}{a \sqrt{P_{S}}\left(1+P_{P}\right)}\right)^{2},
$$




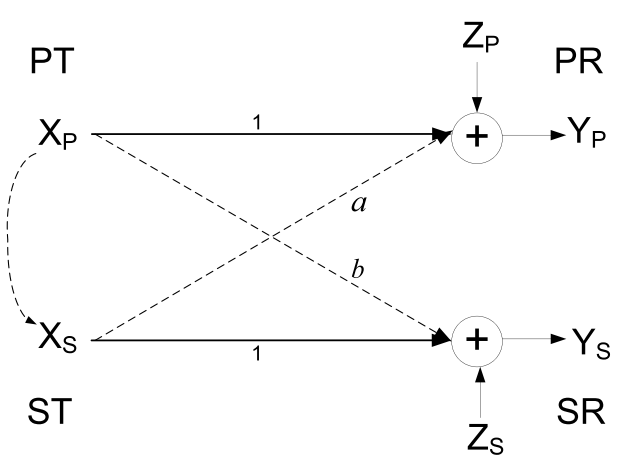

Fig. 3. Diagrama em blocos representado o modelo overlay de rádios cognitivos proposto em [18].

$P_{P}$ é a potência do transmissor primário e $a \leq 1$ e $\alpha$ significa a quantidade da potência dispendida pelo secundário para assistir a comunicação do par primário e pode assumir valores de zero a um. Se $\alpha=0$, nenhuma assistência é oferecida. Ao contrário, se $\alpha=1$, toda a potência do transmissor secundário é empregada para assistir a comunicação do par primário. A restrição para que $a \leq 1$ no modelo em [18] significa que o sistema é afetado por baixa interferência. Ou seja, que o transmissor secundário está bem mais próximo do receptor secundário do que do receptor primário.

Um modelo de comunicação overlay como este é possível devido ao conhecimento a priori da interferência e pelo uso de técnicas sofisticadas de codificação como dirty paper coding [19]. Srinivasa and Jafar [16] mostraram que a capacidade do transmissor secundário com o modelo overlay, eq. (2), pode ser consideravelmente maior do que a capacidade atingível pelo transmissor secundário no modelo interweave, eq. (1). A vantagem evidente do modelo overlay de rádios cognitivos é a possibilidade de ter transmissões simultâneas dentro da mesma região de interferência.

Esta seção é finalizada evidenciando que é possível traçar uma analogia entre o modelo rádio cognitivo de duas chaves em [16] e a definição da região de inteferência em [6]. Quando o nó está transmitindo, os outros nós dentro da região de interferência não podem transmitir, assim como se tivessem suas chaves abertas no modelo de duas chaves. O nó que está ativo pode ser visto como o usuário primário, enquanto os outros nós em seu raio de inteferência são vistos como transmissores secundários. Neste ponto, é interessante indagar sobre o que ocorreria se os nós dentro de uma região de interferência pudessem se comunicar baseados no modelo overlay de rádios cognitivos como em [18], ao invés do modelo de duas chaves. Enquanto um dado nó está transmitindo (o usuário primário), um outro nó em sua região de interferência (usuário secundário) poderia transmitir para um nó diferente. Na próxima seção esta questão será abordada.

\section{RÁdio Cognitivo E WMNs}

Um dos principais desafios na aplicação prática do modelo overlay de rádios cognitivos é a premissa que o transmissor secundário deve conhecer a mensagem do usuário primário antes do transmissor primário iniciar a transmissão. Se o transmissor secundário não tem esta informação a priori (não causal), é possível obtê-la casualmente, se a capacidade do canal entre ambos transmissores for muito maior do que a capacidade do canal entre o transmissor e o receptor primários [11]. Na prática, isso é difícil de implementar e demanda que os transmissores estejam próximos um do outro.

Entretanto, considere o caso de uma WMN onde o nó intermediário está repassando a mensagem para o próximo nó a caminho do gateway. O nó fonte, ou o nó que repassou a mesma mensagem no início da cadeia de saltos, sabe o que está para ser transmitido pelo nó intermediário. Portanto, pode ser visto como um transmissor secundário no modelo overlay de rádios cognitivos, enquanto o nó intermediário seria o transmissor primário. Devido esta particularidade da topologia de uma WMN, e supondo sincronização perfeita, a questão do conhecimento não causal da mensagem do transmissor primário é resolvida.

Em um cenário rádio cognitivo o transmissor primário deveria transmitir com a mesma taxa caso o transmissor secundário não estivesse presente. Aqui, por uma questão de justiça para com todos os nós da rede, temos interesse que as taxas dos transmissores primários e secundários sejam iguais. Neste ponto passamos a considerar o modelo de canal com interferência com conjuntos de mensagem degradadas (ICDMS) conforme discutido em [18], e o qual é a base para encontrar o resultado exibido em (2). As regiões de taxas atingíveis para este canal, a taxa do transmissor primário $R_{P}$ e a taxa do transmissor secundário $R_{S}$, são dadas por [18]:

$$
\begin{gathered}
0 \leq R_{P} \leq \frac{1}{2} \log \left(1+\frac{\left(\sqrt{P_{P}}+a \sqrt{\alpha P_{S}}\right)^{2}}{1+a^{2}(1-\alpha) P_{S}}\right), \\
0 \leq R_{S} \leq \frac{1}{2} \log \left(1+(1-\alpha) P_{S}\right) .
\end{gathered}
$$

Assim, procuramos por valores de $\alpha$ que garantam $R_{P}=$ $R_{S}$ para um dado valor de $a, P_{P}$ e $P_{S}$. Neste caso, e para $a \neq 0, R_{P}$ será menor que a taxa que o primário poderia atingir sem a presença do secundário. Seja $B$ a taxa original do usuário primário. Pares de taxas idênticas $R_{P}=R_{S}=\gamma B$, onde $0<\gamma<1$, podem ser encontradas. $\mathrm{O}$ valor específico de $\gamma$ é função de $P_{P}, P_{S}$ e $a$.

A Figura 4 mostra os valores que $\gamma$ assume para $a$ variando de 0 a 1 e para valores de $P_{P}=P_{S} \in\{1,2,5,10,20,30,40\}$. Da figura podemos ver que $\gamma$ diminui com o aumento de $a$ e com o aumento da potência de transmissão. Este resultado pode ser justificado pelo fato de que tanto com o aumento de $a$ como com o aumento da potência aumenta-se também a interferência provocada pelo secundário no primário. Portanto, mais potência do secundário terá que ser deslocada para cancelar o efeito desta interferência no primário e, consequentemente, menos potência poderá ser usada para sua própria comunicação, diminuindo a taxa atingida pelo par.

Entretanto, no cenário considerado neste artigo, faz mais sentido supor o caso onde a comunicação secundária interfere pouco. Em uma WMN, é justo considerar que o receptor primário e o transmissor secundário não estarão muito próximos, uma vez que eles encontram, pelo menos, um nó 


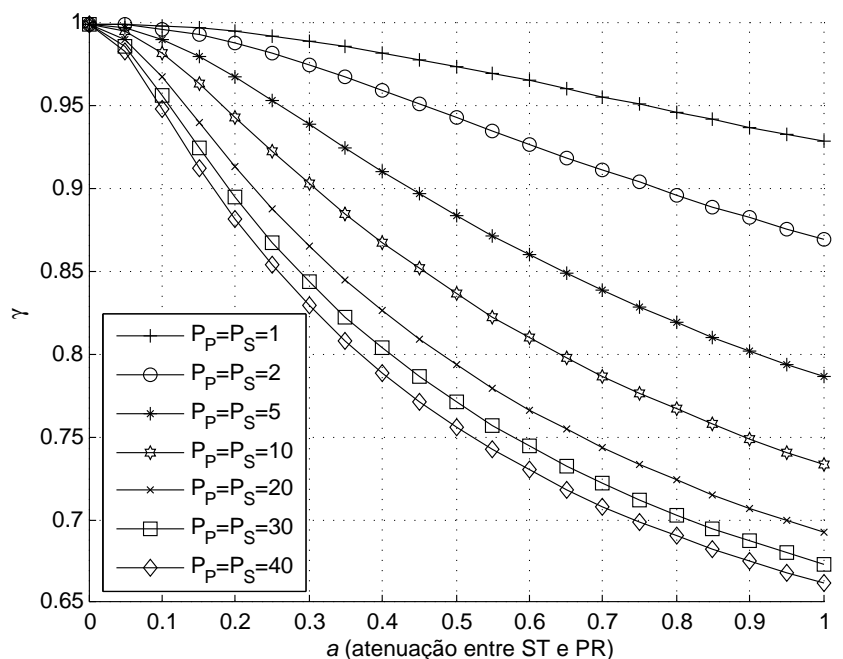

Fig. 4. Fator $\gamma$ em função de $a$ (ganho entre $S T$ e $P R$ ) e de $P_{P}=P_{S}$.

entre eles. Suponha um modelo de perda de percurso logdistância [20] com expoente maior que 2, o ganho do canal entre $P T$ e $P R$ igual a 1 , e que a distância entre $S T$ e $P R$ é duas ou três vezes maior do que a distância entre $P T$ e $P R$. Neste caso, é justo dizer que $a$ será pequeno (menor do que 0,1$)$. Com base neste argumento, deste ponto em diante consideramos que $a=0,1$. Observando a Figura 4 podemos dizer que neste caso mesmo para altos valores de $P_{P}=P_{S}, \gamma$ é próximo de 1 . Além disso, nos resultados a serem apresentados na próxima seção consideraremos que $P_{P}=P_{S}=10$, o que corresponde a uma relação sinal ruído de $10 \mathrm{~dB}$ vista tanto por $S R$ como por $P R$. Neste caso, $\gamma=0.98$. Então, duas transmissões com taxas instantâneas $0.98 B$ bps poderão ocorrer numa determinada região de interferência, onde antes somente uma transmissão com uma taxa instantânea de $B$ bps poderia. Isto significa praticamente dobrar a capacidade de comunicação dentro da região de interferência.

É importante ressaltar que o modelo overlay de rádio cognitivo considera os efeitos das interferências provocadas nas duas transmissões simultâneas dentro de uma mesma região de interferência. Os dois receptores estarão sujeitos a interferência e o transmissor secundário tem condições de resolver as duas interferências sozinho. Esta é uma novidade do modelo overlay de rádio cognitivo em relação a outros métodos propostos na literatura para transmissões simultâneas, como são os casos do physical layer newtwork coding [22] e do trabalho em [23].

\section{RESUltados NumÉRICOS}

De modo a investigar o efeito de empregar o modelo overlay de rádios cognitivos [18] em uma $\mathrm{WMN}$, à princípio será considerado a mesma WMN simples composta por uma cadeia de nós mostrada na Figura 1.

Neste caso, considerando o modelo rádio cognitivo, a segunda transmissão do nó 8 para o nó 7 pode ocorrer no mesmo período de tempo que o nó 6 está repassando para o nó 5 a mensagem previamente enviada pelo nó 8 . A segunda transmissão do nó 8 para o nó 7 será vista como uma transmissão secundária relativa à primeira transmissão

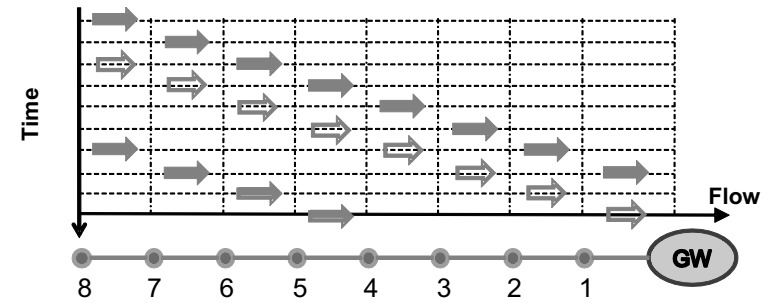

Fig. 5. Exemplo de uma WMN composta de uma cadeia de nós e um gateway. Os nós comunicam-se com seus vizinhos conforme o modelo overlay de rádios cognitivos. As transmissões representadas pelas setas sólidas são consideradas transmissões primárias. As setas vazadas representam as transmissões secundárias.

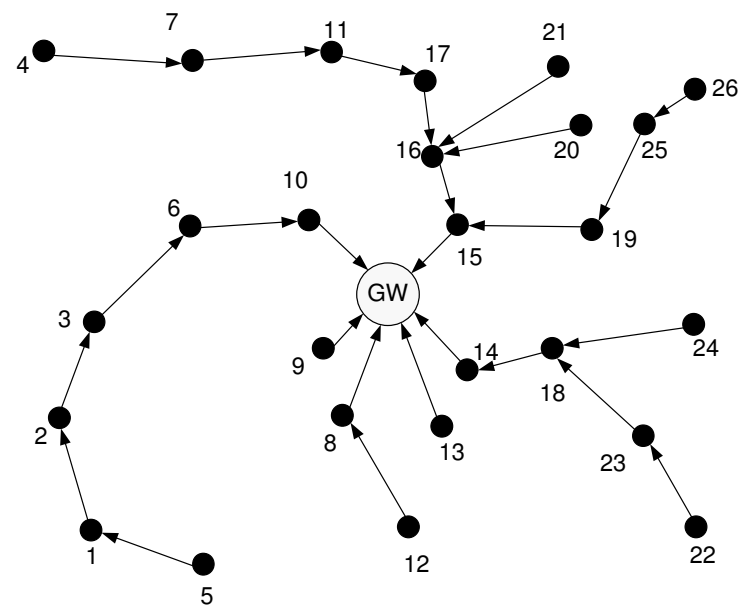

Fig. 6. Topologia gerada aleatoriamente de uma WMN.

do nó 6 para o nó 5, que neste caso será a transmissão primária. Note que na Figura 1 a segunda transmissão do nó 8 ocorre somente durante a primeira transmissão do nó 4 para o nó 3, restrição esta imposta pela região de interferência. Generalizando este exemplo, tem-se o esquema de transmissão mostrado na Figura 5. As transmissões representadas pelas setas sólidas são consideradas transmissões primárias relativas ao modelo rádio cognitivo. As setas vazadas representam as transmissões secundárias que podem ocorrer na região de interferência do par primário uma vez que a mensagem do transmissor primário é conhecida pelo transmissor secundário.

Poderíamos sugerir que a segunda transmissão primária ocorresse durante a transmissão secundária entre os nós 6 e 5. Contudo, isso refletiria um segundo secundário no modelo overlay de rádios cognitivos, o que é uma proposta apresentada na seção $\mathrm{V}$ para futuras investigações. À princípio, o nó 8 deveria ter o conhecimento do que o nó 6 estaria transmitindo, o que siginifica conhecer a mensagem e a forma como esta mensagem foi codificada. A mensagem que o nó 6 vai transmitir é de conhecimento do nó 8 , mas a codificação da mensagem no nó 6 requer o conhecimento do estado dos canais entre os nós envolvidos na comunicação primária e secundária, o que ainda é um problema em aberto.

Comparando as Figuras 1 e 5 pode-se esperar que, usando o modelo rádio cognitivo, a capacidade da rede aumentará. Levando em consideração a mesma definição para o raio de 
interferência como mostrado na Figura 1 (duas vezes o raio de transmissão), pode-se mostrar que a capacidade da rede é de $\gamma B / 3$. Considerando $\gamma=0.98\left(a=0.1, P_{P}=P_{S}=10\right)$, há um aumento de $30 \%$ quando comparado com a capacidade da WMN sem o emprego do modelo overlay de rádios cognitivos (que era de $B / 4$ apenas).

A aplicação do modelo overlay de rádio cognitivo para a cadeia simples é vantajosa para nós afastados de até dois saltos ou mais do gateway. O ganho acima foi obtido para cenário onde o tráfego foi gerado no extremo da cadeia. Para casos onde o tráfego é gerado em nós intermediários, a mesma análise pode ser aplicada considerando que cada nó gerador de tráfego forma uma cadeia simples sobreposta à cadeia original.

Considere agora uma topologia de rede mais genérica. A Figura 6 mostra uma WMN com vinte e seis nós e um gateway. As distâncias entre os nós foram geradas aleatoriamente. O raio de interferência é duas vezes o raio de transmissão, que por sua vez, é aproximadamente o maior salto na Figura 6. Assim, cada nó terá regiões de interferência distintas que devem ser levadas em consideração nos cálculos de capacidade. As setas na Figura 6 indicam os enlaces utilizados para transportar o tráfego em direção ao gateway. É assumido que os nós ativos geram o mesmo volume de tráfego, e que $\gamma=0.98\left(a=0.1, P_{P}=P_{S}=10\right)$. Além disso, garantimos que todos os nós ativos experimentem o mesmo atraso de transmissão em relação ao gateway.

Consideramos um cenário onde seis nós $(4,5,12,22$, 24, 26) geram tráfego. A melhora na capacidade devido à utilização do modelo overlay de rádios cognitivos é de $35 \%$. Para calcular esta melhora na capacidade precisamos considerar todas as diferentes regiões de interferência para os nós envolvidos nas transmissões. A topologia aleatória genérica mostra algumas particularidades do emprego do modelo overlay de rádio cognitivo em WMNs. Por exemplo, quando usuários acessam o gateway diretamente ou quando tem somente um nó intermediário como é o caso do nó 12 , o modelo overlay não traz nenhum ganho porque não há aplicação da transmissão secundária. Além disso, quanto maior for a concentração de nós próximos ao gateway o ganho tende a ser maior do que na cadeia simples, porque as transmissões de um ramo próximas ao gateway bloqueiam as transmissões de outros ramos que tenham nós dentro das regiões de interferência do ramo ativo. Os resultados acima mostram que o emprego do modelo overlay de rádios cognitivos para comunicações entre nós em uma WMN pode aumentar o ganho de capacidade da rede. Entretando, há muitas questões abertas relativas a esta proposta. Por exemplo, como o ganho se comporta com o aumento do tamanho da rede? Como sincronizar os transmissores primário e secundário? $\mathrm{O}$ que aconteceria se permitíssemos duas transmissões secundárias simultâneas, ao invés de somente uma, ou que ramos adjacentes pudessem participar das comunicações secundárias? Os resultados preliminares otimistas descritos aqui nos motivam para aprofundar a investigação destas questões.

\section{COMENTÁRIOS FINAIS}

WMNs e rádios cognitivos são dois assuntos de intensa pesquisa atualmente. Propusemos uma maneira de juntar estas duas idéias. Resultados preliminares mostram que a capacidade de uma WMN pode ser substancialmente aumentada se aplicarmos o modelo overlay de rádios cognitivos para comunicações entre os nós da rede. Este modelo permite transmissões simultâneas dentro de uma região de interferência. Numa rede formada por uma cadeia simples, o aumento da capacidade pode chegar a $30 \%$. Para o exemplo de uma rede gerada aleatoriamente, com uma topologia mais complicada, o ganho de capacidade foi ainda maior. Tais resultados motivam investigações mais aprofundadas nas potencialidades e implicações desta proposta.

\section{REFERÊNCIAS}

[1] I. Akyildiz, X. Wang and W. Wang, "Wireless mesh networks: a survey," Computer Networks, vol. 47, no. 4, pp. 445-487, Mar 2005.

[2] J. Jun and M. Sichitiu, "The nominal capacity of wireless mesh networks," IEEE Wireless Communications, vol. 10, no. 5, pp. 8-14, Oct 2003.

[3] L. Le and E. Hossain, "Multihop cellular networks: potential, gains, research challenges, and a resource allocation framework," IEEE Communications Magazine, vol. 45, no. 9, pp. 66-73, Sept 2007.

[4] P. Gupta and P. R. Kumar, "The capacity of wireless networks," IEEE Trans. on Information Theory, vol. 46, no. 2, pp. 388-404, Mar 2000.

[5] M. Grossglauser and D. Tse, "Mobility increases the capacity of ad-hoc wireless networks," Proc. IEEE Infocom, Apr 2001.

[6] J. Li et al., "Capacity of ad hoc wireless networks," Proc. 7th ACM Int'l. Conf. Mobile Comp. and Net., July 2001.

[7] N. Nandiraju et al., "Wireless mesh networks: current challenges and future directions of web-in-the-sky," IEEE Wireless Communications, vol. 14, no. 4, pp. 79-89, Aug 2007

[8] R. Prasad, "A perspective of layerless communications," Wireless Personal Communications, vol. 44, no. 1, pp. 95-100, Jan 2008.

[9] M. Vu, N. Devroye and V. Tarokh, "An overview of scaling laws in ad hoc and cognitive radio networks" Wireless Personal Communications, vol. 45, no. 3, pp. 343-354, May 2008.

[10] J. Mitola, Cognitive Radio: An integrated Architecture for Software Defined Radio, Ph.D. Dissertation, KTH, Stockholm, Sweden, Dec 2000.

[11] S. Srinivasa and S. A. Jafar, "The throughput potential of cognitive radio: a theoretical perspective," IEEE Communications Magazine, vol. 45, no. 5, pp. 73-79, May 2007.

[12] A. Goldsmith, S. Jafar, I. Maric, S. Srinivasa, "Breaking spectrum gridlock with cognitive radios: an information theoretic perspective," Submitted to Journal on Selected Areas in Communications, 2008.

[13] N. Devroye, P. Mitran, O.-S. Shin, H. Ochiai, and V. Tarokh, "Cooperation and cognition in wireless networks," SK Telecom Review, Special Issue on 4G Spectrum and System Engineering, February 2007.

[14] N. Devroye, P. Mitran, and V. Tarokh, "Limits on communications in a cognitive radio channel," IEEE Communications Magazine, vol. 44, no.6, pp. 44-49, Jun 2006

[15] R. Taranto, H. Yomo, P. Popovski, K. Nishimori, and R. Prasad, "Cognitive mesh network under interference from primary user," Wireless Personal Communications, vol. 45, no. 3, pp. 385-401, May 2008.

[16] S. A. Jafar and S. Srinivasa, "Capacity limits of cognitive radio with distributed and dynamic spectral activity," IEEE Journal on Selected Areas in Communications, vol. 25, no. 3, pp; 529-537, April 2007.

[17] N. Devroye, P. Mitran, and V. Tarokh, "Achievable rates in cognitive radio channels," IEEE Trans. on Information Theory, vol. 52, no. 5, pp. 1813-1827, May 2006.

[18] A. Jovicic and P. Viswanath, "Cognitive radio: an information theoretic perspective," IEEE Int'l. Symp Inf. Theory, Jul 2006. Also accepted in IEEE Trans. on Information Theory.

[19] M. Costa, "Writing on dirty paper," IEEE Trans. on Information Theory, vol. 29, n. 3, pp. 439-441, May 1983.

[20] T. S. Rappaport, Wireless Communications: Principles and Practice, Second Edition, Prentice-Hall, 2002.

[21] IEEE 802.11 WLAN Committee, "IEEE P802.11, the working group setting standards for wireless LANs"Web page: http://grouper.ieee.org/groups/802/11, Current as of Jun 17, 2008

[22] S. Zhang, S.-C. Liew, P. P. Lam, "Physical layer network coding," Proc. ACM Mobicom, 2006.

[23] S. Boppana, M. Sivakumar, J. M. Shea, "The overlapped carrier-sense multiple access (OCSMA) protocol," Proc. IEEE MILCOM, 2007. 